\title{
Monitoring of Tolerance Associative Field and Forecasting of Inter-ethnical Interrelations Problems: Questionnaire Survey in the University Environment of Tajikistan
}

\section{Diloro Iskandarova}

Head of Theoretical and Applied Linguistics Department, Russian -Tajik (Slavonic) University, Doctor of Philology, Professor Faculty of Philology, Department of Theoretical and Applied Linguistics, Russian-Tajik (Slavonic) University Dushanbe Tajikistan1-5; Tursunadze Str., 30, Dushanbe, 734025, Tajikistan; Email: iskandarova@hotmail.com

Zevar Gulova

Senior Lecturer of Department of Theoretical and Applied Linguistics Russian-Tajik (Slavonic) University, Candidate of Science (Philology)

\section{Manizha Davlatmirova}

Associate Professor of Department of Theoretical and Applied Linguistics Russian-Tajik (Slavonic) University, Candidate of Science (Philology)

\section{Nargis Karimova}

Associate Professor of Department of Theoretical and Applied Linguistics Russian-Tajik (Slavonic) University, Candidate of Science (Philology)

\author{
Alexey Fomin \\ PhD Student of Department of Theoretical and Applied Linguistics \\ Russian-Tajik (Slavonic) University, Candidate of Science (Philology)
}

Doi:10.5901/mjss.2015.v6n5s4p35

\section{Abstract}

The problems of tolerance are crucial in modern society. The present article covers the main aspects of tolerance (intolerance), classifies main approaches and methodologies for scientific researches in this area and analyses the results of an associative experiment conducted in the student environment at Khujand State University (Sogd Region, Tajikistan) aimed at monitoring and research of the youth tolerance level. Sometimes misunderstanding and intolerance occur not only between the representatives of different ethnoses but also between the representatives of different regions in one country that results in civil confrontations, as it was in Tajikistan in 1992-1997. Due to the above, Tajik scientific researches on national linguistic worldview and axiological landmarks forming the basis for tolerance/intolerance, existence of stereotypes in the society resulting in the conflicts of different kinds are of great importance. The need in such researches is firstly explained by the necessity of forecasting vital problems in inter-ethnical interrelations between youngsters, development of the policy for tolerant interrelations in the society. The tolerance level monitoring among students in interrelation of cultures allows studying problematic areas, introducing corrective measures aimed at reduction of the number of students having negative attitude to the inter-cultural interrelation and increase of the level of their tolerance.

Keywords: tolerance, ethnical stereotypes, applied aspects of the study, development of tolerance field of the linguistic personality, associative field, questionnaire survey, "personal-strange", "friend-enemy", "motherland-foreign land" oppositions, Tajik, Russian, Uzbek

\section{Introduction}

\subsection{Introduction to the Problem}

It is known that the development of tolerant interrelations is impossible without awareness on peculiarities of behavior, 
traditions, and habits of certain nations. Herewith, it is required to conduct scientific researches on national linguistic, associative and axiological worldviews forming prerequisites for intolerance in the society, occurrence of ethnical stereotypes resulting in inter-ethnical conflicts.

Occasionally, misunderstanding and non-acceptance occurs not only between the representatives of different ethnoses but also between those of different regions in one country resulting in civil confrontation. Breaking social stereotypes, dissociation of regions, radical Islamism, false "Democratization", intolerance between other political and social factors resulted in the war in Tajikistan in 1992-1997.

In this respect, in Tajikistan the scientific researches on national linguistic, associative and axiological worldviews that have prerequisites for intolerance in the society, occurrence of stereotypes resulting in inter-ethnical conflicts, are of high importance. The objective of our research is to monitor the associative field of social consciousness of youth in the university environment of Tajikistan. It should be pointed out that the need in such researches is largely determined by the necessity of forecasting real problems of inter-ethnical interrelation between youngsters, development of the policy for tolerant interrelations between the representatives of different ethnoses.

\subsection{Importance of the Problem}

Although the second half of the $20^{\text {th }}$ century became the epoch of widely spreading struggle against racism and racial, religious and national discrimination for civil, economic, cultural and social rights in the global arena, the beginning of the $21^{\text {st }}$ century showed a growing threat of conflicts and clashes preconditioned particularly by social and ethnical basics of intolerance.

Modern world is characterized by various forms of inter-ethnical confrontation: ethno-territorial conflicts, clashes resulting from inter-religious and inter-ethnical discord, acts of violence on the part of neo-Nazi and extremist organizations, the cases of racism against ethnical migrants, etc. Development of tolerant consciousness may serve as a mechanism for regulation of inter-ethnical contradictions that are based particularly on ethnical and social stereotypes.

The image of a partner for inter-cultural communication is often developed before the direct contact based on the stereotypes - simplified mental representations. The mechanisms of stereotypes development are directly related to the peculiarities of human thinking and psychology. The developed stereotypes acquire high degree of sustainability, are difficult to modify and become a sort of "distorting mirror" in which the blurred or distorted representatives of different groups are reflected. The study of ethno-stereotypes becomes one of the vital problems in the research of ethnical tolerance and development of a tolerance field.

Multi-culture is a characteristic feature of modern society. According to certain researches, a multi-cultural society is characterized by a controversial attitude of the members of one social group to the representatives of other national or cultural groups. This inevitably leads to frequent aggravation of inter-ethnical interrelations which is peculiar to any multiethnical environment of any state (Tihonova, 2011).

Based on the above, the experts consider that the living conditions of most ethnoses in a limited territory result in the growth of inter-ethnical tension. In this regard, the social and psychological interrelations of ethnical groups often acquire a conflict character. Ethnical intolerance today is a real form of display of crisis transformations in a multi-national society (Tihonova, 2011).

Same may be attributed to the problems of religious and other social phenomena that presuppose a minimum of two antagonist parties.

Therefore, an integral part of modern society is a conflict with one of its aspects being a search for the solutions and means and ways for mutually respectful and peaceful co-existence of different social, religious or ethnical groups in a certain territory. This very context gives grounds for the occurrence of "tolerance" that represents a part of conflict competence and one of central notions in respect of any conflict relating to the peaceful co-existence of different cultures (Belozerova, 2011).

\subsection{Different Aspects of Research on Tolerance}

Modern humanitarian scientific disciplines cover almost all aspects of tolerance. There is a great amount of works on the study of this notion from the point of view of philosophy, psychology, conflict management, linguistics, pedagogics, sociology, etc. Each of scientific trends and each of expert scientists tried to study this issue as part of their competencies and from time to time provided findings and examples of the respective problem study as part of neighboring scientific trends. Herewith, to date, on the one hand there is a large amount of thoughts regarding tolerance, and, on the other hand, there are attempts of factual and quantitative evaluation of the problem. 
The notion of "tolerance" which is widely applied today in scientific researches as a way to prevent and solve various types of social conflicts as a certain idea occurred approximately in the $16^{\text {th }}$ century due to religious controversies in Europe. In the $16^{\text {th }}$ and $17^{\text {th }}$ centuries, this term acquired a legal meaning and was applied in the decrees on tolerance, acts on tolerance to people belonging to different confessions (Hamutovskaya, 2012).

Later, due to philosophic ideas of a large number of notionalists from Hobbes, Voltaire, Rousseau to L.N. Tolstoy and M.M. Bakhtin, as well as modern Russian and foreign researchers, the idea of tolerance resulted in the approval of the Declaration of Principles on Tolerance at UNESCO General Conference in 1995. However, to date, we do not have a common understanding, notion or definition of tolerance.

Thus, as it was noted above, currently there is a significant amount of diversified approaches and thoughts regarding tolerance.

It should be noted that scientific researches analyze the notion of "tolerance" as part of a conflict competence and in close connection and coupled with its antonym "intolerance". Both these notions are an integral whole within the theory of conflicts. The study of both these antagonisms in common allows obtaining the most objective result in analyzing different issues related to tolerance.

Looking at tolerance as an object of scientific research even at this stage may result in a certain classification of this notion suggesting a range of sub-categories for this object. By choosing one or several sub-categories one may elaborate on the frames of the object and subject for the study of the tolerance formation and its features.

Ye.Yu. Zhmyrova suggests nine types (sub-categories) of tolerance (intolerance) by objects of intolerance in her work:

1. to other views, ideas, points of view (intellectual);

2. to other ethnos (ethnical);

3. to other religion (confessional);

4. to other culture (inter-cultural);

5. to other gender (gender);

6. to other sexual orientation (sexual);

7. to other health condition (medical);

8. to other age (age-related);

9. to other social group/strata (class) (Zhmyrova, 2006).

Each of the suggested types has its own features and characteristics. Thus, we have a classification of the notion of "tolerance" and can give an initial characteristic to the object of research, and to elaborate on the subject of research related to it.

The point of view or the analysis of the issue of tolerance (intolerance) is also of importance. Here we are talking about the aspects, sides or approaches to the analyzed problem. Analysis of earlier conducted researches allowed determining eight main aspects for the study of tolerance (Fig. 1).

Figure 1 shows that at the junction of culturological, linguistic and didactic aspects additional, derivative trends for the research of the problem under consideration occur. Same applies to the junctions and other aspects of tolerance study but at the stage of preliminary researches, it was not possible to determine clearly shown derivatives from these trends (possibly exclusive of the historical aspect).

Specific place is occupied by the historical aspect. Historical way of the tolerance idea development has already been covered above. Nevertheless, this issue largely concerns philosophic aspect of the problem. As it was stated above, there is no common notion or understanding of tolerance among the researchers and scientists. There is also no common thinking regarding tolerance as a concept, category or idea. On the other hand, from the historical point of view, tolerance (intolerance) has its own stages of evolution. Ye.B. Rashkovskyy determines four general stages of tolerance layers formation:

- Archaic

- Axial

- Modern

- Postmodern (Rashkovskyy, 2003). 


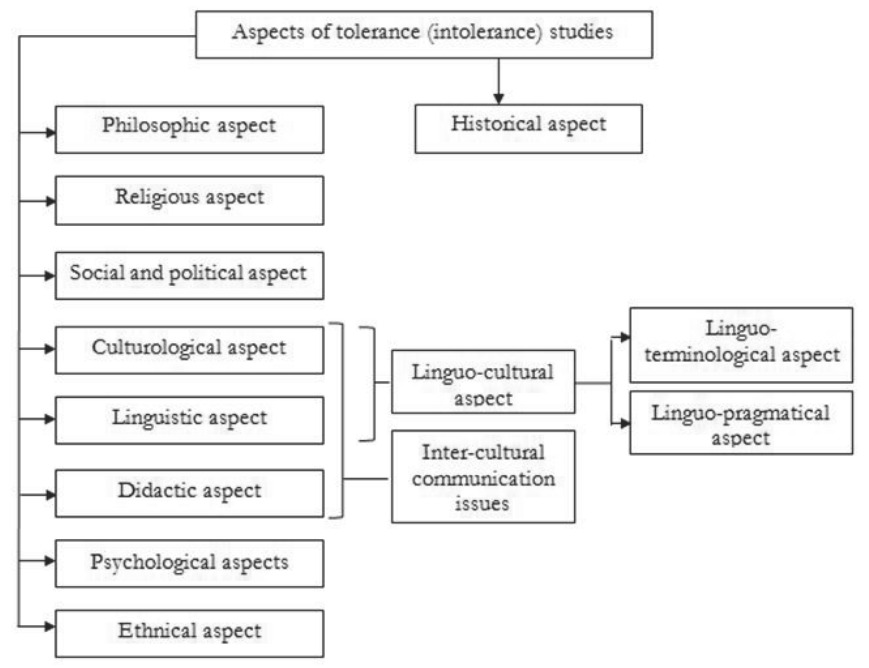

Figure 1. General aspects of tolerance (intolerance) studies.

At the archaic stage basic antithesis "we-they" was developed (in our research we consider them as oppositions "personal-strange"). This antithesis refers to the earliest, infantile, almost animal layers of collective and individual experience of people, to those epochs when a human was perceived as an absolute and non-reasoning affiliation of an initial kinsmen group, i.e. to the primeval epoch.

Axial stage relates to development of general global religions: Judaism, Christianity, Islam, Buddhism, their views and philosophies, notions of "tolerance" and "intolerance" as well as religious wars.

"Modern-tolerance" is connected with the socio-cultural development of the pre-industrial and industrial society. Characteristic features of this stage are the deterministic interpretation of human reality; attitude to a human as an "object" of personal interests, estimations, manipulations; the pursuit of purely technological, procedural solutions to human problems without paying proper attention to their inner - conceptual- content; reductionism, i.e. desire to reduce the whole complex of human contradictions and inconsistencies to a single category (efficiency, social organics, class, race, nation, civilization, geopolitical interest, etc.) and deal with these contradictions with the help of respective simplifying attitude.

General features of the post-modern stage include anti-intellectualism; deliberate and rational appeal to archaic Psyche, archaic mentality, archaic fears and prejudices; not always scrupulous criticism against the richest intellectual and spiritual memory of the people of the Euro-North American area. In addition, this stage is characterized by the emergence of such concept as "political correctness" (Shamsutdinova, 2006).

We consider that at each of those historical stages of the above aspects of tolerance are present in this or that form and are characterized by their own specifics. Consequently, the historical aspect is connected with all other aspects and has joint derivatives.

According to the above, the occurrence of tolerance (through intolerance as well) may be studied not only at a modern stage but in historical retrospectives based on the periodization developed by Ye.B. Rashkovskiy. This gives an opportunity to determine the time frames for the conducted researches. Undoubtedly, the suggested periodization may have different variations, additional periods and sub-periods.

\subsection{State Hypotheses and Their Correspondence to Research Design}

As part of the research, we started studying the issues relating to the analysis of the sources of ethnical intolerance: ethno-stereotypes, difference in axiological worldview of different nations, associative field, and formation of a tolerance field of a linguistic personality that will allow determining the main features of ethno-psychological background of the established inter-ethnic relations in the educational environment of Tajikistan. This will enable to develop recommendations for the application of a series of measures in order to form and promote tolerance among youth. 
Linguistic studies of tolerant consciousness have not been carried out in Tajikistan. We will be the first to conduct a large-scale work on the study of tolerance in the Republic of Tajikistan, a part of which is an associative experiment (AE) in order to build an associative field (AF) for tolerance among youth and prediction of problem areas in inter-cultural communication.

The main goal of this research is to monitor the existing ethnical stereotypes and an associative field of tolerant consciousness by analyzing the results of an associative experiment that will allow determining the sources of intolerance in the society and developing ethnical tolerance in the society.

To achieve the set objective the following tasks need to be implemented:

- Developing research methodology and monitoring ethnical tolerance in the educational environment under the conditions of cultures interrelation;

- Questionnaire survey and associative experiment in order to study the associations with the stimulating words regarding the "personal-strange", "friend-enemy", "motherland-foreign land" oppositions and Tajik, Russian, Uzbek ethnonyms;

- Linguo-cognitive research of the tolerance field of a linguistic personality within the range of various dimensions (associative field, axiological dominants, ethnical stereotypes).

The work on the associative field is still at its initial stage. The residents of the two regions of the country, Khatlon and Sogd regions, were interviewed. We still need to carry out a survey in the universities of Gorno-Badakhshan Autonomous Region and Dushanbe, the capital of Tajikistan, which will allow conducting a comparative analysis of regional, gender, age and other criteria.

This research analyzes the data acquired in Sogd region.

\section{Methods}

\subsection{Analysis of Significant Methods of Research on Tolerance}

An important question in the study of tolerance as a scientific object is a method of investigation. The analysis of the works relating to the subject allowed determining two main approaches, depending on which the corresponding methodology is selected: theoretical and applied.

The main methods applied in the study of tolerance include descriptive-analytical, contrastive-comparative, experimental, quantitative, method of questionnaire survey, polling and interviewing, and a method of associative experiment. The above methods include theoretical methods, such as descriptive-analytical and contrastive-comparative. Other methods are attributed to applied ones.

Applied approach reflected in a quantitative or qualitative factual form represents a state of different aspects of tolerance in the society in the current moment.

Combination of these two approaches results in the third type - analytical. As part of an analytical approach, the conclusions and forecasts regarding the occurrence of conflicts on various grounds (social, religious, ethnic, etc.) are made and the solutions may be provided. However, we believe that this approach is more likely a derivative from the theoretical one or is at the junction of both approaches.

\subsection{Selected Research Methodology}

As a research methodology, we have selected a free (non-directional) association experiment. The choice of this methodology to identify components of the structure of the concept is due to the fact that this type of experiment allows getting closer to real thinking. According to R.M. Frumkina, "in studying associations in an associative experiment, we appeal to the unconscious, deep layer of our Psyche" (Frumkina, 2001). This experiment makes it possible to set unconscious verbal and non-verbal connections of a stimulus word with other words as well as to indirectly identify cognitive features of realities represented by a stimulus word that are relevant for an individual.

Let us characterize the carrying out of experiment. The respondents were offered to answer the questionnaire in a relatively homogeneous by age (18-21 years old) and by educational status (students) group. The first part of the questionnaire represented an associative experiment (a written set of stimulus words was given: "personal", "strange", "friend", "enemy", "motherland", "foreign land", "Tajik", "Russian", "Uzbek", etc.). The group of respondents was instructed to write first words that come to their mind as an answer to the stimulus word).

The second part of the questionnaire included giving answers to the question Which? Relating to stimulus words and is aimed at additional stimulation of respondents for qualitative associations with stimulus words. Ethnonyms were 
accompanied by adjectives, e.g. Tajik, Russian, Uzbek, etc.

We interviewed 171 respondents (students of Khujand State University), and analyzed first reactions. Some respondents refused; therefore, after the sorting 160 questionnaires were selected. The experiment was conducted by the authors of the research that undergone the preliminary briefing regarding the conditions for carrying out of the experiment, i.e.: formulation of tasks and time to be given to the respondents.

The age limit of the respondents (18-21) was selected due to the fact that this specific age is considered the most optimal for the respondents in the associative experiment.

\subsection{Research of the Associative Field}

The selected method of associative experiment is applied to identify an associative field (AF) of the word, which consists of a core and periphery. The role of the associative connections of the words in text formation is obvious. An associative field of a word focuses, directly or indirectly, the linguistic parameters of a word, reflects the diversity of semantic, thematic-situational, and assessment-pragmatic relations, significant for text formation.

Associative connections reflect the communicative properties of words that bear informative-semantic and pragmatic orientation, preconditioned by:

1) linguistics: a) specifics of the lexical meaning; b) stylistic markedness; c) grammatical peculiarities; d) phonetic structure of words, etc.;

2) extralinguistics: a) creative activity of a linguistic personality with different visions the events defined by words identified in his/her consciousness; b) possible thematic and situational orientation of lexical units.

An associative field is developed with the help of responses-reactions of native speakers to the stimulus word. An associative field represents knowledge about the stimulus word in each specific national culture. It should be noted that one of the types of word meaning is associative. N.V. Ufimtseva specifies four advantages of an associative experience:

1. Relatedness of associative reactions with the semantic structure of the language vocabulary;

2. Their dependence on linguistic syntagmatic relations of a word;

3. Based on associative reactions we may conclude on the rules for common use of the words in a speech;

4. Materials of the associative research can be considered as specific for the culture and language, an "associative profile" of the images of consciousness, integrating a mental and sensible knowledge possessed by a certain ethnic group.

Associative fields reflect of the value orientations and stereotypes of linguo-cultural communities. The method of associative experiments makes it possible to study the collective linguistic consciousness as if "from the inside", and therefore allows analyzing the basic oppositions of ethnic consciousness, important in the context of tolerance. Thus, the associative field of tolerance will help highlighting a number of problems prevailing in the linguistic consciousness of youth in Tajikistan.

\subsection{Characteristics of the Experiment Participants}

Venue: Khujand State University named after B. Gafurov, Khujand, Administrative Center of Sogd region, Tajikistan; Total respondents: 171, after sorting - 160;

Nationality: 115 - Tajik, 43 - Uzbek, 2 - Tatar;

Sex: male - 72 , female - 83 , not responded - 5 persons;

Age: $18-21$

\subsection{Justification of the Stimulus Words Selection}

It should be noted that the formation of a tolerance field of a linguistic personality is associated with the identification of five basic concept-oppositions; thus the majority of researches held regarding tolerance (intolerance) from various aspects, were reduced to finding the elements relevant to the following opposition: "love - hate", "luck - bad luck", "friend enemy", "personal- strange", "homeland - foreign land" (Isayeva, 2010).

However, we found it necessary to include a number of additional concepts in the stimulus words, such as "destiny", "environment" and some others. Respondents were also offered stimulus words with ethnonyms (Russian, Tajik, Uzbek) to identify ethnic stereotypes, prevailing in the youth environment of Tajikistan. Furthermore, to stimulate additional associations in line with the oppositions the question which? and adjectives Tajik, Russian, Uzbek were added.

This research covers the findings of analysis of three oppositions "personal-strange", "friend-enemy", "motherland 
- foreign land" as well as ethnonyms.

\section{Results and Discussion}

The opposition "personal-strange" showed that the respondents have an understanding of the limits of the personal environment and attitude to personal and strange, i.e. the limit of tolerance:

personal

House 10, person 7, mother 6, family 4, close person 4, property 3, my 3, life 2, father 2, sister 2, native 2, goal 2, everything belonging to me 2 , something that belongs to me 2 , case 2 , pen 2 , me 1 , parents 1 , brother 1 , husband 1 , acquaintance 1 , friend 1 , beloved 1 , everything personal 1 , personal 1 , yours 1 , ours 1 , property 1 , things 1 , jewelry 1 , car 1 , hearth 1 , number 1 , telephone 1 , education 1 , character 1 , opinion 1 , place 1 , way 1 , town 1 , people 1 , school 1 , wish 1 , strange 1 , something that belongs to you 1 , consciously take decisions 1 , everything beautiful 1 ,

strange

unknown 12 , strange person 6 , person (people) 6 , enemy 3 , not personal 3 , thing 3 , divide 3 , not native 2 , land 2 , strange place 2, personal 2, culture 2, remote 2, Uzbeks 2, cannot give life to other cities 2, city 1, world 1, happiness 1 , love 1, self-cognition 1, water 1, close 1, king 1, Germans 1, KSU1 1, I-Phone 1, no 1, stranger 1, unknown 1, someone I don't know 1, no close connection 1, a person not dear to you 1, not relatives 1.

Analysis of reactions to the stimulus word "personal" showed that most of the respondents included the following in the limits of their personal environment: property (21), "their" people - relatives, family and its members (19), close people (13); home, hearth (11), synonymous pronouns (mine, yours, ours, etc. -6 ) and separate (1 of each) by associations: character, opinion, education, place, way, wish, etc. beautiful.

There were also descriptive reactions, like something that belongs to you, consciously take a decision, everything

Among reaction words to "personal" the word way appeared that was one of the stimulus words suggested in the questionnaire.

Strange for the respondents appeared mainly strange (21) or unknown people (10), place or land (8), culture (3), enemies (3), people of other nationalities (3), culture. Moreover, there were also strange happiness, love, king, telephone, etc. mentioned.

The reaction words to "strange" included enemy, love, happiness, Uzbeks that were also suggested as the stimulus words in the questionnaire.

"Friend-enemy" opposition:

During the questionnaire survey of these oppositions an additional question which? was asked to stimulus words. Herewith, an additional stimulus to answers was given:

friend

best 7, good 7, loyal 7, close 7: (close person, the closest person 2, the closest), trusted person 6 (people I trust), true 6, real 5, mother 5, names of friends 5: (Farangis, Dildora, Ruhshona, Firuza, Iskandar), kind 4, faith 3, enemy 3, support 3 (help each other in difficult times and be together), friends can be of 3 types (choni, nomi, zaboni) 32, beloved 2 , clever 2 , friends that understand each other 2 , old friend 1 , brotherhood 1 , brother 1 , father 1 , my husband 1 , rescuer 1 , fellow 1 , adviser 1 , protector 1 , sister 1 , friend 1 , class-mates 1 , group-mates 1 , nobody 1 , betrayer 1 , faithful 1 , dear 1 , healthy 1 , cheerful 1 , honest 1 , happy 1 , happiness 1 , friendship 1 , tenderness 1 , sincerity 1 , loyalty 1 , respect 1 , help 1 , support 1 , way 1 , forever 1 , helped 1 , someone that will keep your secrets 1 , balm for soul at sad times 1 , that will not leave in grief 1 , always close 1 ,

Which?

good 18, loyal 16 , real 8 , close 7 , best 5 , faithful 4 , caring 4, kind 4, beloved 4, honest 3 , dear 2 , old 2 , dedicated 1 , brave 1, reliable 1, dear 1, polite 1, nice 1, unique 1, die 1, enemy 1.

Enemy

Malicious 14, bad 12, friend 5, cruel 4, hatred 3, public enemy 3, dangerous 3, names (of personal enemies)- 3 :

${ }^{1}$ KSU - Khujand State University, where the questionnaire survey was conducted

2 The respondents repeatedly named associations connected with the examples from literature. In this case an association is connected with an example from the poem by Saadi (a poet of the 13th century) that divides friends into three types: noni (friends for feasts), nomi (friends for talks), and choni (friends for spirit): Friends for feasts, conversations and spirit Of those three types are all of merit?

Share your table with friends for feasts but keep them away; Share your time with friends for talks; But trust only friends for spirit; You can even drink a glass of poison for them! 
(Sayora 2, Eshonkulov), mutobik 2, envy 2, bad person 2, someone that looks at another person with evil eyes 2, revenge 2 , insolency 1 , arrogance 1 , distrust 1 , betrayal 1 , foe 1 , aggressor 1 , venger 1 , neighbor 1 , me 1 , murderous 1 , ugliest 1 , unfriendly 1 , unfaithful 1 , envious 1 , terrible 1 , badly 1 , tough 1 , close 1 , invader 1 , harmful 1 , angry 1 , black 1 , powerful 1 , health 1 , noisy 1 , stupid 1 , reckless 1 , against me 1 , a person that hates another person 1 , a person that I hate $1 ;$ I even don't want to talk about him/her 1; maybe I have enemies but for me it doesn't matter 1, happy when you are in trouble 1 , a person that wish you bad 1, doesn't wish you good 1.

Which?

Malicious 16, bad 13 , cruel 7 , dangerous 3 , envious 3 , strange 2, tough 2, black 2, scary 2, strong 2, my 2 , indecisive 1 , nasty 1 , unfriendly 1 , unfortunate 1 , unlucky 1 , bitter 1 , murderous 1 , harmful 1 , scoundrel 1 , not good 1 , not kind 1, misfortune 1, Jew 1, disgusting 1, poor 1 , spiteful 1 , disobedient 1 , hateful 1 , hypocrite 1 , big 1 , detestable 1 , Christian 1, close 1, cunning 1, different 1.

The findings show that a friend in the linguistic consciousness of respondents mainly has such qualities as loyal and faithful-28, good-25, real, true-21, close-14, best-12, kind-8. For 9 respondents a friend is a family member (mother, father, brother, sister, husband), 5 persons named their friends. A friend can be clever, understanding, honest, dedicated, reliable, rescuer, adviser, protector, the one that will not betray, will not give away secrets, will not leave in a difficult situation, always near, and a "balm for soul". Associations with an enemy-4 and betrayer-1 were also named.

The word happiness also appeared among the stimulus words.

Reaction to the stimulus word enemy was mainly presented in the words evil-30, bad, not good - 27, cruel and tough - 15. The word enemy is also associated with hatred - 16, an enemy can be the worst, envious, murderous, unfriendly, scary, spiteful, cunning; in addition an enemy can be detrimental, angry, stupid, noisy, unlucky and disobedient. The representatives of other religions were also named among enemies; however, such reactions are not common.

Reactions-associations are not numerous: foe, invader, avenger, hypocrite; arrogance, disdain, distrust, betrayal.

The word stranger (2) was also among the reaction words.

"Motherland - foreign land" opposition:

Motherland

Mother 31, Tajikistan 16 (beloved Tajikistan 1, Tajikistan (we are proud of) 1), place 16 (of birth 8, where I live 2, that we love and live at 1 ; where we attain lawful age 1 ; where I can live freely and happily 1 ), Khujand 7 , native 6 , personal 5 , country 4 , my 4 , Sughd 4 , mother with children 3 , homeland 3 , native land 3 , home 3 , soil 2 , love 2 , beautiful 2, service 2, city 1, village 1, middle 1, Kyrgyzstan 1, dear 1, mountainous 1, peace and order 1, love 1.

Which?

dear 16, beloved 15, beautiful 10, my 5, good 4, well-arranged 3, big 3, personal 2, mother 2, Tajikistan 1, Tajik 1 , free 1 , the best 1 , mountainous 1 , rich 1 , green 1 , light 1 , valuable 1 , unforgettable 1 , small 1 , unpredictable 1 , darling 1 , kindness 1.

\section{Foreign land}

Toponyms 13: (America 3, Moscow 1, China 1, Dubai 1, India 1, Bukhara 1, Korea 1, Germany 1, Russia 1, England 1, Isfara 1), wandering 5, not native 4 , torture 4, be far away from motherland 4, loneliness 4 (lonely 3), strange country 3, being far from parents 2, step-mother 2, migrant 2, any other country, apart from Tajikistan 2, not good 1, foreign culture 1 , other nation 1 , difficulty 1 , disadvantages 1 , expectation 1 , far from close people 1 , interesting 1 , motherland 1 , melancholy 1 , foreign language 1 , away from home 1 , live in foreign country 1 , with no family 1 , tree 1 , Chinese 1, nothing 1, our 1, friendship 1, separation 1, not a motherland 1, tough 1, deep 1, KSU 1, difficult life 1, no close people 1 , to be at foreign land 1 , missing mother 1 , I have no idea 1 , a person that has a mother and a father 1 , lonely people 1 , kuzhbina 31

Which?

Bad 4, person 3, names of countries 2 (Arabiston 1, Russia 1), strange 2, foreign 2, tough 2 , deep 2, lonely 1, rich 1 , beautiful 1 , temporary 1 , not good 1 , difficult $1, \operatorname{dim} 1$, far 1 , stranger 1 , not needed 1 , dark 1 , not native 1 , wanderer 1 , foreign language 1.

Motherland is associated mainly with the place of living - 50 (Tajikistan, Sughd, Khujand, Kyrgyzstan), mother 37, synonyms were also given: native land, homeland. For a lot of respondents it is home, country, land - 11. Understanding of the word "Motherland" shows that our youth is patriotic, since the qualitative characteristics in definition are as follows: dear-22, beloved-15, beautiful - 12, the best, good, well-arranged, free, mountainous, rich, green, dear, unforgettable, big, small, unpredictable.

\footnotetext{
${ }_{3}^{3}$ In Tajik language reduplications are often used; in this case reaction to "kuzhbina" represents an echo-word.
} 
The reaction word personal was noted among the studied stimulus words.

The reaction to the stimulus word "foreign land" was mainly represented by countries and cities not native for the respondents - 17. The words associated with the word "foreign land" were as follows: wondering, torture, loneliness, foreign country, migrant, step-mother, difficulty. The qualities of the foreign land: bad, strange, not known, tough, deep, lonely, not good, difficult, dim, far, strange, not needed, dark, not native, but rich and beautiful.

Analysis of reactions in most cases shows negative attitude of respondents to foreign land since this stimulus is associated primarily with the separation from home, migration and wondering that demonstrates extreme affection to native land and non-acceptance in most cases of living in a foreign country.

Specific interest was paid to the existing ethnical stereotypes in youth environment. The respondents were offered to characterize Tajiks, Russians, Uzbeks, i.e. ethnoses, living in the territory of a country and closely contacting in all areas.

The questionnaire survey provided the following findings:

Tajik

hard-working 12, hospitable 10, beautiful 10, kind 9, food 10 (pilaf 3, shakarob 2, manty 2, sambusa 2, dishes 1 ), toponyms 8 (Dushanbe 6, Tajikistan 1, Temurmalik 1), native places 8 (mountains 6, motherland 2), sensible 4, we 4, patriot 3 , appearance 15 (dark eyes 3 , dark complexion 3 , dark hair 2, beautiful figure 2 , dark eyebrows 1 , beard 1 , average height 1, beautiful eyes and eyebrows 1, small 1), clothes 3 (scullcap 1, clothes 1, satin dress 1), good 2, lazy 2 , word 2, language 2, bright sun 2, history 1, nationality 1, nation 1, culture 1, Muslim (female) 1 (+ Muslim (male) 1), Arian 1, person 1, state language1, nice (kind) nation 1, generous 1, loyal 1, honest 1, powerful 1, modest 1, black 1, white 1 , mountainous 1 , wise people 1 , benevolent 1 , cultural 1 , sociable 1 , polite 1 , not quite clever 1 , Uzbek 1 , employee 1 , ofarin 1 , national values 1 , movie 1 , songs 1 , a lot of colors 1 , city in bloom 1, working with confidence 1 , not missing 1.

Tajik (adjective)

Dishes 19 (osh (pilaf) 10, food 2 (delicious), fruit 2; kurutob 2, sambusa 1, shakarob 1, kitchen 1), Tajik language 8, clothes 7 (national dress (different from all others) 3+ (skullcap 2, chapan 1, kerchief 1), nature/places 11 (mountains 4 , nature 2 (beautiful), heavenly places $1+$ places 1 , lake 1 , river 1 , motherland 1 ), water 4 , traditions 4 , friendliness 3 , people 3, toponyms 3 (Dushanbe 1, Khujand 1, Pamir 1), family 2, hospitality 2, guys 2, external traits 2 (long hair 1, dark eyes and eyebrows 1 ), university 2 , history 1 , person 1 , flag 1 , culture 1 , song 1 , poet 1 , movie 1 , cinema 1 , holiday 1 , Navruz 1, employee 1, mosque 1, gymnasium 1, Russian 1, sweet 1, gold 1, ruby 1, gissarets 1.

Most respondents associate ethnonym "Tajik" with native places 30 (toponyms are also mentioned (11) and mountains, nature, place, etc.); with different dishes of Tajik cuisine 29, external looks - 17, items of national clothes - 10 , different character traits, such as hard-working 12 , hospitable 10 , beautiful 10, kind 9 , sensible 4 , nice, kind people, generous, loyal, honest, powerful, modest, black, white, mountainous, wise people, benevolent, cultural, sociable, polite. Apart from positive characteristics, such characteristics as lazy and not quite clever are also mentioned.

Russian

Appearance 54 (red-haired (ginger-haired, gingery) 23, blue eyes 17) + light-skinned 7 (white 1, white person 1 , blonde 1, green eyes 1, little white 2, light 2, light-haired 1, tall 1), places 11 (Russia 4, Moscow 4, Red Square 2, Kremlin 1), character 9 , honest 7 , language 6 , clever 4 , person 2 , songs 2 , singers 2 , good 2 , wise 3 , kind 3 , cultural 2 , healthy 2 , cunning 1 , hospitable 1 , hard-working 1 , simple 1 , understanding 1 , brave 1 , coffee 1 , tradition 1 , temple 1 , culture 1 , matryoshka 1, kokoshnik 1, balalayka 1, uniform 1, city 1, hair 1, writer 1, beautiful square 1, Putin 1, Nyusha 1, a little 1, drunkard 1, know their rights 1, nobody but that 1, loves pleasures 1.

Russian (adjective)

People 14 (guy 3, person 2, people 2, fairy-tales 2, intelligence 2, female singers 2, celebrities 1, writer 1, singer 1 , scientist 1 , simple people 1 , blonde girls 1 , old woman 1, relative 1), gastronomy 12 (cuisine 5 , pancakes 2, coffee 2, chocolate 2, dish 1), character 10, toponym 4 (St. Petersburgh 2, Moscow 1, Kremlin 1), song 4, music 3, language 3, ballet 2, literature 2, Putin 1, Nikolay Baskov 1, intelligence 1, knowledge 1, talent 1, nation 1, tradition 1, words 1 , anecdotes 1 , subjects 1 , book 1 , hat 1 , telephone 1 , building 1 , baths 1 , beautiful city 1 , movie 1 , eyes 1 , Tajik 1 , Chinese 1 , kind 1 , sincere 1.

The respondents had exclusively positive associations with the word "Russian". There was only one negative reaction - drunkard.

A lot of respondents noted external looks - 47, such as color of hair, skin and eyes (red hair, blue eyes, white skin), the word "Russian" was also associated with toponyms - 15 (Russia, Moscow, St. Petersburgh, etc.), with different people - 21 (specific people - 4: Putin, singers Baskov and Nyusha, simple Russian person/people or people of certain professions). A lot of respondents noted Russian character - 19. A lot of reactions were also connected with Russian culture (literature, music, songs, ballet) or realia (balalayka, matryoshka, kokoshnik). Qualitative characteristics: honest 7 , 
clever 4, kind 4, wise 3, good 2, cultural 2, cunning, hospitable, hard-working, simple, understanding, brave, sincere, knows his/her rights.

Uzbek

Tashkent 4, Bukhara 4, Samarkand 4, Uzbekistan 3, hospitable 4, people that are difficult to understand 3, working person (hard-working 4), appearance 12 (beautiful people 5, dark eyebrows 1, dark eyes 1, having moustache 1, bearded 1 , dark-skinned 1 , average height 1 , bold 1 ,); neighbor 3 , songs 3 , talkative 3 , kind 5 , people 3 , pilaf 3 , good 2, language 2 , nationality 2 , me 2 , country 2 , movie 2 , insensible 3 , sociable 1 , tender 1 , sincere 1 , happy 1 , modest 1 , benevolent 1 , amateur 1, dishes (lagman 1, pilaf 2, dishes 1), brother of Tajik 1, Tajik 1, hamzaboni mo ${ }^{4}$, books 1 , dilozor ${ }^{5} 1$, misanthrope 1, enemy 1, enemy of Tajiks 1 , not handsome 1 , betrayer 1 , hypocrite 1 , mean 2 , not cultural 1 , will never become a human 1 , talks a lot 1 , not talkative 1 , custom 1 , TV-series 1 , music 1 , video clips 1 , movies 1 , movie makers 1 , customs and rites 1, morals 1, boarder 1, skullcap 1, chuzbek 1.

Uzbek (adjective)

Pilaf 14 , cinema 7 , movie 5 , language 5 , actors 3 , cars 3 , music 2 , eyes 2 , hospitable 2 , clothes 2 , songs 2 , dance 1, actor 1, culture 1, family 1, dekhanin 1, Samarkand citizen 1, student 1, airplanes 1, Tashkent 1, fool 1, lagman 1 , watermelon 1, dish 1, tradition 1, outfit 1, satin 1, earring 1, nation1, gas 1, happiness 1, Kirgiz 1, well-bred people 1, too modern 1, forty Uzbek pigtails 1.

Reaction to the stimulus word "Uzbek" was mainly with the words relating to culture 24 - (music, songs, movies, etc.); in addition, pilaf-16 and other dishes of national cuisine, external looks- 15 , toponyms-15. Positive qualities of a person were noted-28: hospitable 4, hard-working 4, sociable 1, tender 1, honest 1, happy 1 , modest 1, benevolent 1 , etc. and negative - 12: mean 2, misanthrope, enemy, enemy of Tajiks, not handsome, betrayer, hypocrite, not cultural, etc.

The attitude to Uzbeks was controversial. Uzbeks are not only the citizens of the neighboring country but also have been living side by side with Tajiks for many years. Nevertheless, the policy of expropriation introduced by the government of Uzbekistan at the years of independence resulted in the adverse changes in the relations between the countries and the people. In 1992, air communication between Tajikistan and Uzbekistan was cancelled; strict visa regime was introduced (reaction word "border"), supplies of Uzbek gas were cut off (reaction word "gas"). There were attempts to isolate Tajikistan from economic point of view (geographic factor), etc. and affected the mentality of Tajikistan citizens. Taking the above into account, the results of the questionnaire survey in Sughd region bordering with Uzbekistan the citizens of which traditionally had a good attitude to the fraternal nation were quite unexpected.

The conducted questionnaire survey give us understanding of the components of the associative field of tolerance in the students' environment.

\section{Conclusion}

As it was noted, the main objective of the questionnaire survey was to determine ethnical stereotypes in the students' environment and level of tolerance based on the understanding of oppositions "personal-strange", "friend-enemy", "motherland-foreign land", "love-hatred", "happiness-unhappiness". We assumed that the knowledge of associative fields of basic linguo-cultural oppositions "personal-strange", "friend-enemy", "motherland-foreign land", and other ethnonyms of the closely connected nations would encourage tolerance of the linguistic consciousness in the inter-cultural communication. "Linguistic consciousness is the part of cognitive consciousness that is expressed in a word and is associated with the respective object in communication. It is studied with the help of linguistic" (Nerovnaya). Different methods and techniques of the experiment and questionnaire survey include the meaning of linguistic units. The obtained description is later subject to cognitive interpretation for the concept modeling. The concept is modeled taking into account the linguistic and experimental data.

Having analyzed the obtained data, we came to the conclusion that the respondents' reactions to the studied oppositions were calm, weighted, non-aggressive demonstrating their non-conflicting and tolerant attitude.

A lot of reaction words to different stimuli (personal, friend, and motherland) are connected with dear people, especially with parents, which is natural in the traditional Tajik society where youngsters respect elderly people and have close connection with their relatives during their whole life.

Attitude to the motherland, native land, places of birth and living, home and hearth is also extremely warm and respectful showing patriotism and attachment to native land.

\footnotetext{
${ }^{4}$ Some words are difficult to translate from Tajik language in one word; for example "hamzaboni mo" is translated as "the one having common language with us"

${ }^{5}$ Dilozor (hurting one's heart), the one that hurts
} 
A friend is also of great importance in the life of youngsters. Relatives, especially mothers, are also attributed to friends. Friends are idealized; they are given such qualities as intelligence, kindness, sincerity, dedication, reliability, etc.

At the same time, the attitude to strangers and strange places is quite alert and negative. From old times Tajiks' attitude to foreign land was mainly negative. People are ready to travel but not always hope to come back. Currently, foreign land is associated with migration and the need to earn for a living away from one's home; thus, a foreign land is associated with a step-mother, wondering, and loneliness, the need to be away from home and relatives, suffering privations. All this is a proof of great attachment to home, difficulties in adaptation to new conditions and intolerance (or not understanding) of strange cultures.

Analysis of the reaction to ethnonyms demonstrates certain problems in interrelations of Tajiks and Uzbeks; however, the attitude of all respondents (including Tajiks and Uzbeks, comprising $30 \%$ of respondents) to Russians was quite kind and respectful.

The conducted research defines the components of the "tolerance" concept structure, ratio of associative reactions in the structure of the mentioned concept. Further analysis of other set oppositions allows adding updated data to the structure and the comparative analysis by regional characteristics will show similarities and differences in the associative field of youngsters from different regions of the country.

We consider such researches helpful in elaborating on the tolerance phenomenon, demonstrating how young generation feels, perceives and comprehends this notion.

Questionnaire survey and associative experiment regarding the main aspects of tolerance in youth environment allows determining problematic areas and developing a set of measures (trainings, master-classes, interactive courses) on formation of a tolerant linguistic personality.

Development of the methodology and organization of measures on formation of ethnical tolerance in the educational environment under conditions of interrelation of cultures enables to increase the number of students with positive ethnical identity, raise the level of their tolerance, and reduce the number of students negatively perceiving the inter-cultural interrelation. As a result, the students participating in the programs on formation and development of ethnical tolerance will receive not only knowledge on ethno-psychological peculiarities of the representatives of different ethnoses and experience of inter-cultural interrelation but will also learn to consciously apply them for the solution of the problems that they might face.

\section{Acknowledgements}

The research is financed as part of the project "On Cognitive and Ethno-psycho-linguistic Research on Tolerance and Inter-ethnical Interrelations" within the University Development Program in 2014-2016.

We would like to show appreciation to the Russian-Tajik (Slavonic) University for the financing of the project "On Cognitive and Ethno-psycho-linguistic Research on Tolerance and Inter-ethnical Interrelations" within the Programme for the University Development in 2014-2016.

We would also like to express gratitude to the lecturers of Khujand State University for their assistance in questionnaire survey.

\section{References}

Abolin, B.I. (2009). Kontseptsiya "tolerantnost" v kognitivno-duskursivnom aspekte [Concept of "Tolerance" in Cognitive-Discursive Aspect]. Dissertation abstract of the Candidate of Science (Philosophy). - Ekaterinburg [in Russian].

Asmolov A. (Ed.) (2001). Vek tolerantnosti [Century of Tolerance] Scientific and Journalistic Bulletin. Chief Editor - Moscow: Moscow State University [in Russian].

Belozerova, A.S. (2011). O semanticheskom pole ponyatiya "tolerantnost" [On Semantic Field of "Tolerance" Notion]. Bukketin of Northern (Arctic) Federal University. Series: Humanitarian and Social Science. No.4 [in Russian].

Cherkasova, G.A. Formalnaya model assotsiativnogo issledovaniya [Formal Model of Associative Research]. Retrieved from http:/litclaim.ru/Library/Articles/publications_Cherkasova_Galina/Cherkasova34/Cherkasova34.html\#1Etap

Frumkina R.M., (2001). Psiholingvistika (Psycholinguistics). - Moscow: "Akademiya" Publishing House [in Russian].

Hamutovskaya, S.V. (2012) Politicheskaya tolerantnost: kontseptualizatsiya ponyatiya [Political Tolerance: Conceptualization of the Concept]. // Sociologic Almanac. No.3, (pp.223 - 229) [in Russian].

Hertzen RGPPU (2007). Tehnologii formirovaniya politicheskoy, etnicheskoy i religioznoy tolerantnosti [Technologies for Formation of Political, Ethnical and Religious Tolerance] Educational and methodological guide. - St. Petersburg: RGPPU Press [in Russian].

Isayeva, Z.Sh. (2010). Kategoriya "tolerantnost" v nauchnoy kommunikatsii [Category of "Tolerance" in Scientific Communication]. I/Bulletin of Chelyabinsk State University, (pp.49 - 52). [in Russian]. 
Koryapina, Yu. V. K voprosu o kognitivnom komponente kommunikativnoy tolerantnosti [To the Issue of Cognitive Component of Communicative Tolerance] //Knowledge. Understanding. Skills. No.2, (pp.270-273) [in Russian].

Malkova V.K. (Ed.) (2002). Diagnostika tolerantnosti v sredstvah massovoy informatsii [Diagnostics of Tolerance in Mass Media] Moscow: IEA RAN.

Nerovnaya, N.A. Tolerantnost i terpimost [Tolerance and toleration]. Retrieved from http:/luchebilka.ru/kultura/9758/index.html?page=6 [in Russian]

Petuhova, T.N. (2012). Teoretiko-metodologicheskiy analiz ponyatiya "tolerantnost" [Theoretical and Methodological Analysis of the Notion of "Tolerance"]. I/Bulletin of South-Ural State Universith. Series: Law. No. 20, (pp.18-23). [in Russian].

Rashkovskiy, Ye.B. (2003) Plasty Neterpimosti: filosofskiye zametki [Layers of Intolerance: Philosophic Notes]. (pp. 61-67)//Issues of Philosophy. No.4 [in Russian].

Shamsutsinova, Ye. Yu. (2006) Tolerantnost kak kommunikativnaya kategoriya (lingvisticheskiy i lingvodidakticheskiy aspect [Tolerance as a Comminicative Category (Linguistic and Linguo-Didactical Aspect)]. Dissertation thesis of the Candidate of Science (Philology). - Moscow, (p.621). [in Russian].

Tihonova, Ya.G. (2011) Formirovaniye mezhetnicheskoy tolerantnosti v podrostkovoy srede [Formation of Inter-Ethnical Tolerance in Juvenile Environment]. [pp. 576-578]//Bulletin of Orenburg State University. №. №16 [in Russian].

Zherebilo, T.V. (2011) Terminy i ponyatiya: metody issledovaniya $i$ analiza teksta [Terms and Notions: Methods of Research and Text Analysis]. Dictionary and reference book. - Nazran: Piligrim LLC [in Russian].

Zhmyrova, Ye.Yu. (2006). O ponyatii tolerantnost i yeye vidah [On the Notion of "Tolerance" and lts Types] (pp. 1265 - 1269)//Bukketin of Tambov State Technical University, No.4B, vol. 12 [in Russian]. 